\title{
A IMPORTÂNCIA DO DIREITO À EDUCAÇÃO PARA A CONSECUÇÃO DO DESENVOLVIMENTO SUSTENTÁVEL EM CONTEXTOS DE EMERGÊNCIA
}

\author{
Natielli Efigênia Mucelli Rezende Veloso* \\ Letícia Mirelli Faleiro Silva Bueno**
}

\begin{abstract}
Resumo: O direito à educação é, atualmente, parte indissociável da noção de desenvolvimento sustentável - a qual permeia as discussões privadas e públicas, figurando como grande necessidade de nosso tempo. Contudo, pouco estudo é dedicado a como esse direito é tratado em contextos de emergência. O presente artigo pretende se debruçar sobre essa questão e, assim, analisar a importância do direito para a consecução do desenvolvimento sustentável em contextos de emergência. Para tanto, serão utilizadas pesquisas bibliográficas e documentais, com o procedimento metodológico dedutivo.
\end{abstract}

Palavras-chave: Direito à Educação, Desenvolvimento Sustentável, Emergências, Crises, Atuação Humanitária

\section{THE IMPORTANCE OF THE RIGHT TO EDUCATION IN THE ACHIEVEMENT OF SUSTAINABLE DEVELOPMENT IN EMERGENCY CONTEXTS}

\begin{abstract}
The right to education is, currently, an essential part of the concept of sustainable development - which permeates the private and public discussions, appearing as a great necessity of our times. This paper intends to analyze this matter and, in doing so, comprehend the importance of this right to the achievement of sustainable development in emergency contexts. In order to do so, bibliographical and documental researches will be used, with a deductive methodological procedure.
\end{abstract}

Keywords: Right to Education, Sustainable Development, Emergencies, Crisis, Humanitarian Actions

\footnotetext{
* Bacharel em Direito pela Universidade Federal do Estado de Minas Gerais - UFMG. Pós-graduada em Direito Penal pela Newton Campos. Mestranda em Proteção dos Direitos Fundamentais pela Universidade de Itaúna. Advogada. Endereço postal: Rodovia MG 431 - Km 45 (Trevo Itaúna/Pará de Minas) - Caixa Postal 100 - CEP: 35.680-142 - Itaúna/MG. Endereço eletrônico: natielliveloso@gmail.com.

** Bacharel em Direito pelas Faculdades Integradas do Oeste de Minas. Pós-graduada em Ciências Criminais pela Universidade Gama Filho. Pós-graduada em Direito do Trabalho e Processual do Trabalho pela Faculdade Pitágoras. Mestranda em Proteção dos Direitos Fundamentais pela Universidade de Itaúna. Advogada. Endereço postal: Rodovia MG 431 - Km 45 (Trevo Itaúna/Pará de Minas) - Caixa Postal 100 - CEP: 35.680-142 - Itaúna/MG. Endereço eletrônico: faleiro.bueno.adv@hotmail.com.
} 


\section{INTRODUÇÃO}

O direito à educação ${ }^{1}$, historicamente presente em peso nos tratados de Direito Internacional, figurando, pela primeira vez, na Declaração Universal de Direitos Humanos $(1948)^{2}$, é, atualmente, parte indissociável da noção de desenvolvimento sustentável - a qual permeia as discussões privadas e públicas, figurando como grande necessidade de nosso tempo. Contudo, pouco estudo é dedicado a como esse direito é tratado em contextos de emergência ${ }^{3}$. De fato, se em condições consideradas estáveis e, em certa medida, "normais” é comum a falta de priorização por parte dos governos, em momentos de crise ou emergências o direito à educação corre o risco de ser colocado em segundo plano frente a outras necessidades vistas como prioritárias por relacionarem-se com questões de vida ou morte.

Assim, atividades como estabelecimento de escolas, preparação de professores e conscientização das comunidades afetadas quanto à importância da manutenção das crianças na escola - dando enfoque especial para as que normalmente seriam excluídas, como meninas, deficiente físicos e mentais - são tradicionalmente desenvolvidas apenas depois que a crise é cessada, sendo esse o momento adequado, segundo defensores de uma visão tradicional, para preocupar-se com assuntos “menores” e ligados ao desenvolvimento sustentável. Contudo, o enfoque atualmente dado à questão da sustentabilidade tem permitido que tal visão seja questionada e que uma nova abordagem, a qual dá o devido destaque ao direito à educação, seja defendido e praticado.

\footnotetext{
${ }^{1}$ Educação é compreendida aqui, conforme instruído pela UNESCO, da seguinte forma: “[...] the term education is thus taken to comprise all deliberate and systematic activities designed to meet learning needs. This includes what in some countries is referred to as cultural activities or training. Whatever the name given to it, education is understood to involve organized and sustained communication designed to bring about learning” (UNESCO, 1997, pará. 6).

2 Artigo 26: “1. Toda a pessoa tem direito à educação. A educação deve ser gratuita, pelo menos a correspondente ao ensino elementar fundamental. O ensino elementar é obrigatório. O ensino técnico e profissional dever ser generalizado; o acesso aos estudos superiores deve estar aberto a todos em plena igualdade, em função do seu mérito; 2.A educação deve visar à plena expansão da personalidade humana e ao reforço dos direitos do Homem e das liberdades fundamentais e deve favorecer a compreensão, a tolerância e a amizade entre todas as nações e todos os grupos raciais ou religiosos, bem como o desenvolvimento das atividades das Nações Unidas para a manutenção da paz; 3.Aos pais pertence a prioridade do direito de escolher o género de educação a dar aos filhos.” 3Resta essencial esclarecer em que consistiria a "emergência" aqui trabalhada. Pode-se afirmar que ela englobaria todas situações em que desastres por razões humanas ou naturais destroem, dentro de um curto período de tempo, as condições normais de vida, cuidado e estruturas estatais - inclusive as educacionais - e, portanto, perturbam e prejudicam o progresso ou atrasam a concretização dos direitos humanos locais, como o direito à educação (ONU, 2008, p. 4). Tais situações podem ser causadas por conflitos armado e todos tipos de desastres naturais, como terremotos, furacões e tsunamis.
} 


\section{A IMPORTÂNCIA DO DIREITO À EDUCAÇÃO PARA A CONSECUÇÃO DO DESENVOLVIMENTO SUSTENTÁVEL EM CONTEXTOS DE EMERGÊNCIA}

A fim de nos debruçarmos sobre a questão, procederemos, primeiramente, uma análise das previsões internacionais quanto ao direito à educação. Em seguida, realizaremos um estudo sobre a necessidade de priorização do desenvolvimento sustentável em emergências, bem como sua ligação com o direito à educação, e, por fim, concluiremos sobre a importância do direito à educação para esse desenvolvimento sustentável no contexto de crises, ressaltando qual abordagem de atuação humanitária seria mais adequada: a tradicional, que relega a educação para um contexto posterior, ou a com um viés de direitos humanos, em que o direito a educação busca ser assegurado desde um primeiro momento.

Com relação à metodologia utilizada, o tipo de pesquisa será a bibliográfica e documental, vez que procederemos a investigação da literatura jurídica pertinente, bem como das convenções, convênios e acordos de direitos humanos que tratam do direito à educação. O procedimento metodológico que será usado é o dedutivo, pois se partirá de conceitos amplos e teorias do Direito para aplica-las na especificidade da garantia ao direito à educação em emergências. Por fim, sobre os procedimentos técnicos, serão feitas análises interpretativa, comparativa e teórica.

\section{PREVISÃO DO DIREITO À EDUCAÇÃO EM NORMAS DE DIREITOS HUMANOS}

Há uma grande gama de instrumentos internacionais que preveem o direito à educação, perpassando o direito internacional dos direitos humanos, o direito internacional humanitário e o direito penal internacional. São considerados como os instrumentos com dispositivos mais relevantes no que concerne à educação em contextos de emergência: as quatro Convenções de Genebra relativas à Proteção de Pessoas Civis em Tempos de Guerra (1949) e os Protocolos Adicionais (1977); o Pacto Internacional de Direitos Econômicos, Sociais e Culturais (1966); e a Convenção sobre os Direitos da Criança (1989); os Estatuto de Roma para o Tribunal Penal Internacional (ANDERSON et al., 2011, pp. 89-90-91).

No que diz respeito às Convenções de Genebra, todos os membros das Nações Unidas são signatários e muitos consideram-na de natureza costumeira (ANDERSON et al., 2011, p. 89, rodapé). Os obrigados de acordo com essas convenções são os Estados e todas forças 
armadas atuando em conflitos, bem como os combatentes e forças ocupantes. Os detentores de direitos são os civis e não-combatentes. Sobre o direito à educação, o artigo 52 criminaliza os ataques direcionados intencionalmente contra estruturas civis, inclusive escolas, ${ }^{4}$ e o artigo 4(3)(a) do Segundo Protocolo estabelece a obrigação de prover às crianças cuidado, auxílio e educação $^{5}$. Nesse sentido, cabe destacar, entra a contribuição do Estatuto de Roma, o qual oferece meios para a judicialização da violação do direito à educação por meio de ataques contra escolas $^{6}$

No que diz respeito ao Pacto Internacional de Direitos Econômicos, Sociais e Culturais, destaca-se que o artigo 13 estabelece o direito de todos à educação, sendo a educação primária compulsória e disponível para todos. Já a educação secundária e a superior devem ser acessíveis e disponíveis a todos, bem como a busca pelo desenvolvimento de um sistema de escolas, com programa de bolsas e melhoramento das condições materiais dos professores ${ }^{7}$. Ressalta-se que

\footnotetext{
${ }^{4}$ Artigo 52: “1. Os bens de caráter civil não serão objeto de ataques nem de represália. São bens de caráter civil todos os bens que não são objetivos militares como definido no parágrafo 2. 2. Os ataques limitar-se-ão estritamente aos objetivos militares. No que concerne aos bens, os objetivos militares se limitam aqueles objetos que por sua natureza, localização, finalidade ou utilização contribuam eficazmente para a ação militar ou cuja destruição total ou parcial, captura ou neutralização, ofereça nas circunstâncias do caso presente uma vantagem militar definida. 3. Em caso de dúvida a respeito de um bem que normalmente se presta a fins civis, tal como um lugar de culto, uma casa ou outra moradia, ou uma escola, estar sendo utilizado para contribuir eficazmente para a ação militar, será presumido que não está sendo utilizado com tal propósito.”
}

${ }^{5}$ Artigo 4.3(a): “3. Serão proporcionados às crianças os cuidados e a ajuda de que elas necessitam e, em particular: a) receberão uma educação, incluída a educação religiosa e moral, conforme aos desejos dos pais ou na falta desses, das pessoas que tenham a sua guarda;[...]”

${ }^{6}$ Artigo 8(2)(e)(iv): “1. O Tribunal terá competência para julgar os crimes de guerra, em particular quando cometidos como parte integrante de um plano ou de uma política ou como parte de uma prática em larga escala desse tipo de crimes. 2. Para os efeitos do presente Estatuto, entende-se por "crimes de guerra": [...] e) As outras violações graves das leis e costumes aplicáveis aos conflitos armados que não têm caráter internacional, no quadro do direito internacional, a saber qualquer um dos seguintes atos:[...] iv) Atacar intencionalmente edifícios consagrados ao culto religioso, à educação, às artes, às ciências ou à beneficência, monumentos históricos, hospitais e lugares onde se agrupem doentes e feridos, sempre que não se trate de objetivos militares;”

7 Artigo 13: “ 1. Os Estados Partes do presente Pacto reconhecem o direito de toda pessoa à educação. Concordam em que a educação deverá visar ao pleno desenvolvimento da personalidade humana e do sentido de sua dignidade e fortalecer o respeito pelos direitos humanos e liberdades fundamentais. Concordam ainda em que a educação deverá capacitar todas as pessoas a participar efetivamente de uma sociedade livre, favorecer a compreensão, a tolerância e a amizade entre todas as nações e entre todos os grupos raciais, étnicos ou religiosos e promover as atividades das Nações Unidas em prol da manutenção da paz. 2. Os Estados Partes do presente Pacto reconhecem que, com o objetivo de assegurar o pleno exercício desse direito: a) A educação primaria deverá ser obrigatória e acessível gratuitamente a todos; b) A educação secundária em suas diferentes formas, inclusive a educação secundária técnica e profissional, deverá ser generalizada e torna-se acessível a todos, por todos os meios apropriados e, principalmente, pela implementação progressiva do ensino gratuito; c) A educação de nível superior deverá igualmente torna-se acessível a todos, com base na capacidade de cada um, por todos os meios apropriados e, principalmente, pela implementação progressiva do ensino gratuito; d) Dever-se-á fomentar 


\title{
A IMPORTÂNCIA DO DIREITO À EDUCAÇÃO PARA A CONSECUÇÃO DO DESENVOLVIMENTO SUSTENTÁVEL EM CONTEXTOS DE EMERGÊNCIA
}

o tratado segue o princípio geral de não-descriminação e igualdade no que diz respeito à educação, fundado no artigo 26 da Declaração Universal dos Direitos Humanos - a qual, muito embora não seja vinculante per se, serviu de base para os tratados vinculantes que se seguiram.

\section{Por sua vez, a Convenção sobre os Direitos da Criança tem amplo escopo de aplicação,} pois consiste na convenção mais amplamente ratificada no mundo. Ela possui grande relevância no que tange à educação nas emergências - alguns argumentam que é a convenção mais importante nesses casos (ANDERSON et al., 2011, p. 90, rodapé) - vez que a educação primária, a qual é assentada em sólidas bases em diversos instrumentos internacionais - diz respeito, na maioria dos casos, às crianças. O artigo $28^{8}$ especificamente prevê o direito à educação, notadamente da educação primária compulsória e disponível gratuitamente para todos, bem como do desenvolvimento de diferentes formas de educação secundária e de fazer com que a educação superior seja acessível a todos. Adicionalmente, o artigo $29^{9}$ traz os

\begin{abstract}
e intensificar, na medida do possível, a educação de base para aquelas pessoas que não receberam educação primaria ou não concluíram o ciclo completo de educação primária; e) Será preciso prosseguir ativamente o desenvolvimento de uma rede escolar em todos os níveis de ensino, implementar-se um sistema adequado de bolsas de estudo e melhorar continuamente as condições materiais do corpo docente. 1. Os Estados Partes do presente Pacto comprometem-se a respeitar a liberdade dos pais e, quando for o caso, dos tutores legais de escolher para seus filhos escolas distintas daquelas criadas pelas autoridades públicas, sempre que atendam aos padrões mínimos de ensino prescritos ou aprovados pelo Estado, e de fazer com que seus filhos venham a receber educação religiosa ou moral que esteja de acordo com suas próprias conviç̧ões. 2.Nenhuma das disposições do presente artigo poderá ser interpretada no sentido de restringir a liberdade de indivíduos e de entidades de criar e dirigir instituições de ensino, desde que respeitados os princípios enunciados no parágrafo 1 do presente artigo e que essas instituições observem os padrões mínimos prescritos pelo Estado. ”
\end{abstract}

${ }^{8}$ Artigo 28: “1. Os Estados Partes reconhecem o direito da criança à educação e, a fim de que ela possa exercer progressivamente e em igualdade de condições esse direito, deverão especialmente: a) tornar o ensino primário obrigatório e disponível gratuitamente para todos; b) estimular o desenvolvimento do ensino secundário em suas diferentes formas, inclusive o ensino geral e profissionalizante, tornando-o disponível e acessível a todas as crianças, e adotar medidas apropriadas tais como a implantação do ensino gratuito e a concessão de assistência financeira em caso de necessidade; c) tornar o ensino superior acessível a todos com base na capacidade e por todos os meios adequados; d) tornar a informação e a orientação educacionais e profissionais disponíveis e accessíveis a todas as crianças; e) adotar medidas para estimular a freqüência regular às escolas e a redução do índice de evasão escolar. 2. Os Estados Partes adotarão todas as medidas necessárias para assegurar que a disciplina escolar seja ministrada de maneira compatível com a dignidade humana da criança e em conformidade com a presente convenção. 3. Os Estados Partes promoverão e estimularão a cooperação internacional em questões relativas à educação, especialmente visando a contribuir para a eliminação da ignorância e do analfabetismo no mundo e facilitar o acesso aos conhecimentos científicos e técnicos e aos métodos modernos de ensino. A esse respeito, será dada atenção especial às necessidades dos países em desenvolvimento"

${ }^{9}$ Artigo 29: "1. Os Estados Partes reconhecem que a educação da criança deverá estar orientada no sentido de: a) desenvolver a personalidade, as aptidões e a capacidade mental e física da criança em todo o seu potencial; b) imbuir na criança o respeito aos direitos humanos e às liberdades fundamentais, bem como aos princípios consagrados na Carta das Nações Unidas; c) imbuir na criança o respeito aos seus pais, à sua própria identidade cultural, ao seu idioma e seus valores, aos valores nacionais do país em que reside, aos do eventual país de origem, e aos das civilizações diferentes da sua; d) preparar a criança para assumir uma vida responsável numa sociedade livre, com espírito de compreensão, paz, tolerância, igualdade de sexos e amizade entre todos os povos, grupos étnicos, nacionais e religiosos e pessoas de origem indígena; e) imbuir na criança o respeito ao meio ambiente. 2. 
objetivos da educação, como, por exemplo, que ela deve imbuir nas crianças o respeito aos direitos humanos, às liberdades fundamentais e aos princípios consagrados na Carta da ONU.

Deve-se, também, salientar que no contexto dos Tribunais Internacionais de Direitos Humanos, tal direito é plenamente garantido. Pode-se destacar, por exemplo, a posição da Corte Interamericana de Direitos Humanos, que na Opinião Consultiva $n^{\circ} .17$, de 28 de agosto de 2002, considerou ser parte do direito da criança a uma vida decente a garantia do direito à educação ${ }^{10}$. Assim parte essencial e intrínseca a uma vida digna passa a ser o respeito ao direito à educação, vez que viabilizaria condições para o crescimento pessoal do indivíduo oportunizando que seu status seja alterado no decorrer da vida através de contínuas oportunidades de acesso à educação (CIDH, 2002, p. 66, § 88). Mais do que isso: em Opinião Concordante posterior ao posicionamento da Corte em si, o juiz brasileiro Antônio Cançado Trindade dá valorosa lição de direito internacional ao expressar que as crianças são, por si sós, sujeitos de direito internacional, merecendo ter protegidos os seus direitos na qualidade de seres humanos que são, sendo o direito à educação possuidor de uma relevância transcendental e superior aos demais (CIDH, 2002, p. 99, § 52).

Conforme visto, o direito à educação - principalmente no que tange à educação primária - é embasado ostensivamente nas normas de direitos humanos que, cabe destacar, não são suspensas em momentos de emergência. Com efeito, conforme destacado em relatório apresentado perante às Nações Unidas em 2008, o direito à educação em emergências é sempre legalmente exigível e, portanto, as crianças têm sempre o direito a irem à escola, independentemente dos desafios do contexto em que vivem (ONU, 2000, p. 2). Essa garantia é especialmente necessária no que concerne aos indivíduos mais vulneráveis, os quais tendem a ter seus direitos mais afetados perante as inseguranças, desastres e conflitos. Dessa forma, ganha especial importância a maneira que esse direito será tratado no âmbito das intervenções humanitárias.

\footnotetext{
Nada do disposto no presente artigo ou no Artigo 28 será interpretado de modo a restringir a liberdade dos indivíduos ou das entidades de criar e dirigir instituições de ensino, desde que sejam respeitados os princípios enunciados no parágrafo 1 do presente artigo e que a educação ministrada em tais instituições esteja acorde com os padrões mínimos estabelecidos pelo Estado."

${ }^{10}$ No § 84 da Opinião, esclarece-se: "It should be highlighted that the right to education, which contributes to the possibility of enjoying a dignified life and to prevent unfavorable situations for the minor and for society itself, stands out among the special measures of protection for children and among the rights recognized for them in Article 19 of the American Convention” (CIDH, 2002, p. 65, § 84).
} 


\section{DESENVOLVIMENTO SUSTENTÁVEL E EMERGÊNCIAS: A NECESSIDADE DE PRIORIZAÇÃO}

Primeiramente, cabe esclarecermos em que consistiria o desenvolvimento sustentável. Em 1987 a Comissão Mundial sobre Meio Ambiente e Desenvolvimento publicou o seu relatório intitulado "Nosso Futuro Comum”, também referenciado com frequência como “Relatório Brundtland”. Lá, o termo “desenvolvimento sustentável” é definido como o “desenvolvimento que atende às necessidades do presente sem comprometer as possibilidades de gerações futuras de atenderem às suas próprias necessidades (tradução nossa) "11 (CMMAD, 1987, p. 41).

O relatório ainda salienta que os dois conceitos essenciais dentro dessa definição são: "necessidades", termo com o qual deve-se compreender que prioridade deve ser dada àqueles mais pobres e marginalizados; e que a organização social e estado tecnológico devem ser limitados pelas capacidades do meio ambiente (CMMAD, 1987, p. 41). Portanto, o crescimento populacional deve ser orientado pelos recursos disponíveis, sob a pena da ocorrência de um desastre ecológico. O nosso desenvolvimento de conhecimentos e tecnologia servem para potencializar nossos recursos, mas, em última instância, os limites existem e a sustentabilidade demanda que devemos garantir acesso à essas condições de vida às gerações presente e futuras.

Assim, resta claro que, desde as primeiras delimitações do conceito de desenvolvimento sustentável, especial foco era dado para a situação dos mais empobrecidos e marginalizados, o que ressalta a essencialidade da atenção ao desenvolvimento sustentável em momentos de crise, pois essas circunstâncias servem para aprofundar as dificuldades daqueles mais vulneráveis em nossa sociedade. Inclusive, no mesmo relatório, ao analisarem a situação emergencial de fome na África, afirmou-se que auxiliar meramente através do fornecimento de alimentos é uma reação de curto-prazo que serve apenas para dar respostas parciais ao problema: a verdadeira

\footnotetext{
${ }^{11}$ No original: "Sustainable development is development that meets the needs of the present without compromising the ability of future generations to meet their own needs."
} 
solução para os contextos de emergência viria do desenvolvimento sustentável (CMMAD, 1987, p. 65).

Mas pode-se ir além nessa conceituação, pois a visão atual abarca uma sustentabilidade que não se limita a aspectos econômicos, sociais e ambientais. Conforme a posição de Juarez Freitas, sustentabilidade é compreendida aqui como:

"(...) o princípio constitucional que determina, com eficácia direta e imediata, a responsabilidade do Estado e da sociedade pela concretização solidária do desenvolvimento material e imaterial, socialmente inclusivo, durável e equânime, ambientalmente limpo, inovador, ético e eficiente, no intuito de assegurar, preferencialmente de modo preventivo e precavido, no presente e no futuro, o direito ao bem-estar." (FREITAS, 2016, p. 52)

Esse redimensionamento da importância do desenvolvimento sustentável no decorrer dos anos culminou na criação, por parte das Nações Unidas, do Programa das Nações Unidas para o Desenvolvimento, o qual tem assumido, nos últimos anos, a vanguarda no que diz respeito à implementação do ideal de desenvolvimento sustentável ao redor do mundo. Com efeito, o objetivo estratégico do Programa para o período de 2014-17, como um todo, é ajudar que os países atinjam, simultaneamente, a erradicação da extrema pobreza e a redução significativa das desigualdades e exclusões (PNUD, 2016).

Dessa forma, essa visão atualizada do desenvolvimento sustentável - a qual tem assumido cada vez mais relevância no cenário internacional - serve para realçar sua premente necessidade no contexto de emergências, visto que objetiva a viabilização das condições de uma vida equilibrada e promissora, as quais podem ser excessivamente prejudicadas se não for dada a atenção devida ao desenvolvimento sustentável desde o primeiro momento nas situações de emergência. Para tanto, faz-se essencial o direito à educação, que, conforme veremos abaixo, serve de instrumento viabilizador do desenvolvimento sustentável.

\section{A IMPORTÂNCIA DA EDUCAÇÃO PARA O DESENVOLVIMENTO SUSTENTÁVEL}




\section{A IMPORTÂNCIA DO DIREITO À EDUCAÇÃO PARA A CONSECUÇÃO DO DESENVOLVIMENTO SUSTENTÁVEL EM CONTEXTOS DE EMERGÊNCIA}

Desde o primeiro momento em que o desenvolvimento sustentável foi apoiado pela Assembleia Geral das Nações Unidas, em 1987, a importância da educação para esse fim tem sido discutida (MCKEOWN, 2002, p. 10). Contudo, isso apenas ganhou contornos adequados de definitividade em 2015, quando a Assembleia Geral adotou a Agenda de Desenvolvimento Sustentável de 2030, a qual definiu dezessete objetivos de desenvolvimento sustentável, sendo o quarto objetivo intitulado "Educação de Qualidade” - e busca garantir a educação de qualidade inclusiva e igualitária, promovendo oportunidades vitalícias de aprendizado para todos (UNESCO, 2017, p. 06).

Assim, o tipo de educação que deve ser priorizada, segundo essa renovada ótica de indissolubilidade com o desenvolvimento sustentável - o qual ganha, cada vez mais, contornos de enfoque prioritário global - é aquele que empodera os indivíduos a terem decisões responsável com relação à integridade do meio ambiente, viabilidade econômica e justiça social para gerações presentes e futuras. Não basta mais uma educação que apoie o mero crescimento econômico com padrões de consumo insustentáveis. Assim, tal educação preocupada com desenvolvimento de competências sustentáveis deve ser parte integral de todos os níveis educacionais: desde pré-escolas ao nível superior de estudos (UNESCO, 2017, p. 07).

As metodologias que devem ser priorizadas são aquelas que promovem a integração e não apenas um estudo teórico de tópicos como mudança climática, pobreza e consumo sustentável. Portanto, as metodologias devem ser orientadas para a tomada de ações, com pedagogia transformativa que apoia o aprendizado autônomo, participativo, orientado para a solução de problemas, que se desenvolve de maneira interdisciplinar e transdisciplinar, ligando o aprendizado formal ao informal (UNESCO, 2017, p. 07).

Em condições ideais, portanto, a educação, segundo apontado nos objetivos de desenvolvimento sustentável das Nações Unidas, deve almejar ser universal e dinâmica, de maneira a responder aos desafios das mudanças dos mercados de trabalho, avanços tecnológicos, urbanização, migração, degradação natural e pobreza persistente (UNESCO, 2015, p. 26). As nações se comprometeram, dessa forma, com buscar o fim das diferenciações de gênero na educação, para garantir uma educação de qualidade inclusiva a todos e que se estenda durante toda a vida dos indivíduos (UNESCO, 2015, p. 08). Contudo, resta nos questionarmos: e quando as condições não forem mais as ideais? Quando estivermos diante de 
situações em que o rule of law está ameaçado, por conta de ser um momento de emergência, a educação e seu objetivo final de incentivar o desenvolvimento sustentável ainda deve ser priorizada? As reflexões abaixo buscam responder esses possíveis questionamentos.

\section{A EDUCAÇÃO E O DESENVOLVIMENTO SUSTENTÁVEL EM EMERGÊNCIAS}

Como visto acima, a educação serve de catalisador importante para o desenvolvimento sustentável e isso é particularmente verdade nos momentos de emergência, em que as comunidades afetadas estão em particular situação de vulnerabilidade. Isso é ainda mais gravoso para aquelas parcelas da sociedade que tradicionalmente tem experiências de exclusão, como os deficientes, as mulheres e os que vivem em condição de pobreza.

Um exemplo da ação positiva da educação em momentos de crise consiste nos impactos econômicos positivos da garantia a esse direito, sendo que a economia é um dos aspectos estatais que mais se enfraquece em emergências. Com efeito, melhoras na educação ajudam na redução da pobreza e no crescimento econômico. Estudos apontam que, à nível pessoal, cada ano adicional de estudo aumenta os ganhos do indivíduo em média $10 \%$ e que isso se traduz também à nível nacional com um aumento de 0,58\% do PIB per capita para o aumento nacional da média de tempo estudado em um ano (DIDHAM; OFIE-MANU, 2015, p. 96). A educação em emergências ganha especial importância como um meio de combater a pobreza extrema, a qual é uma ameaça mais iminente nessas circunstâncias, e serve como um meio de proteger as comunidades mais afetadas - principalmente os mais vulneráveis - de serem explorados, pois a educação aumenta a oportunidade de que façam contratos de trabalho seguros (UNESCO, 2014, p. 01).

Além de servir como catalisador da luta contra a pobreza, a educação serve, em emergências, como um meio de contenção de doenças, as quais se espalham com maior facilidade em crises, vez que o Estado não se encontra aparelhado de maneira eficaz para combater surtos, vacinar sua população ou investir em higiene básica. Nisso, cabe ressaltar a importância da educação materna: quando educada, a mãe sabe reduzir os fatores de risco que 


\section{A IMPORTÂNCIA DO DIREITO À EDUCAÇÃO PARA A CONSECUÇÃO DO DESENVOLVIMENTO SUSTENTÁVEL EM CONTEXTOS DE EMERGÊNCIA}

expõe a criança a doenças (UNESCO, 2014, p. 03). Um exemplo disso é que, quando há um investimento na educação materna, a incidência de mortalidade por diarreia - que se prolifera com facilidade em emergências - cai em até 30\%, pois as mães sabem da importância de administrar a reidratação oral e de continuar a alimentação normalmente. Outras doenças comuns nesses contextos também podem ser evitadas com a devida atenção à educação, como por exemplo a malária e, até mesmo, a AIDS (UNESCO, 2014, p. 04).

A educação também é importante para garantir um uso adequado de energia e recursos minerais, cujo acesso pode ser limitado em crises. Por exemplo, onde a água não está em estado adequado para consumo humano, muitas crises sanitárias podem ser evitadas pela educação, pois os indivíduos compreenderão a importância de filtrar ou ferver a água antes do consumo. Além disso, através da educação há um interesse maior na preservação dos recursos hídricos em si (UNESCO, 2014, p. 07).

Tais exemplos tratados denotam com clareza os efeitos positivos da garantia ao direito à educação em contextos de emergências, pois nessas circunstâncias frequentemente há um agravamento da situação dos mais vulneráveis, servindo esse direito como um meio de resguardá-los. Com efeito, a crise se desenrola para esses indivíduos com particular gravidade, servindo o direito à educação como um meio de assegurar uma vivência digna para aqueles cujas circunstâncias tendem a piorar e a serem expostos a um risco especial de exploração e mortalidade. Portanto, cabe vermos qual a melhor maneira de assegurar esse direito nas intervenções humanitárias, de forma a atender às necessidades de desenvolvimento sustentável dos indivíduos afetados.

\section{O MOMENTO ADEQUADO DE PRIORIZAÇÃO DO DIREITO À EDUCAÇÃO EM EMERGÊNCIAS}

A despeito da evidente essencialidade do direito em questão, a posição tradicional no que tange às atuações humanitárias em contextos de emergência defende que, num primeiro momento, o direito à educação não deve ser objeto de investimentos ou priorizado de qualquer forma. Segundo os defensores dessa visão, a educação diria respeito a um passo posterior à 
estabilização do país, sendo ligada, na essência, ao desenvolvimento das pessoas - o que não consistiria em prioridade inicial da ação humanitária (ONU, 2000, p. 02). Portanto, ONGs e doadores têm sido reticentes em despender recursos com as atividades ligadas ao asseguramento desse direito em atuações humanitárias que ocorrem em contextos de emergência, relegando-o para um segundo momento.

Uma atuação pautada apenas no viés tradicional humanitário era - e é - por muitos considerada mais fácil de ser desenvolvida e aceita pelos Estados em geral, vez que é consoante com os já estabelecidos princípios humanitários de neutralidade, imparcialidade e independência, vistos como sustentáculo da ação de agências e ONGs internacionais (DAVIS, 2015, p. 39). A introdução de uma perspectiva de direitos humanos foi vista por muitos de maneira temerária, como se diminuísse o espaço humanitário e prejudicasse o momento de atuação em que a prioridade é salvar vidas (FOX, 2001, pp. 283-284).

Contudo, no decorrer dos anos desenvolveu-se um crescente consenso no sentido de que a atuação em emergências não deve ser focada apenas em evitar que as pessoas morram, mas também em cuidar de como elas vivem. Portanto, gerações podem se passar até que, enfim, a estabilidade seja reassegurada e para que então, finalmente, a educação seja objeto de atenção e investimentos. Isso equivaleria a negar a incontáveis indivíduos - geralmente, os mais vulneráveis - um direito com potencial de ser um catalisador de mudanças positivas em suas vidas.

De fato, muitos aspectos do desenvolvimento local são afetados pela ausência da garantia à educação, sendo que ela consiste numa séria obstrução a questões como implementação de medidas de saúde adequadas, proteção física e mental de crianças e adolescentes e aprendizagem de métodos mais eficazes de gerenciamento de recursos hídricos, elétricos e alimentares. Dessa forma, resta patente que os impactos negativos nas vidas das pessoas e das comunidades afetadas não podem ser reduzidos à mera questão da sobrevivência: vivem numa crise constante que os destitui de qualquer possibilidade de ter a consecução adequada de seus direitos humanos e de seu potencial de desenvolvimento

Assim, mais coerente com a relevância da educação na vida do ser humano, a abordagem mais adequada para as atuações humanitárias é uma que se pauta nos direitos humanos. Nessa perspectiva, a caridade e a benevolência são insuficientes: os indivíduos em 


\section{A IMPORTÂNCIA DO DIREITO À EDUCAÇÃO PARA A CONSECUÇÃO DO DESENVOLVIMENTO SUSTENTÁVEL EM CONTEXTOS DE EMERGÊNCIA}

contextos de emergência devem ser sujeitos de direito, capazes de demandar que seus direitos sejam providos (ONU, 2000, p. 01). Caberiam aqui atividades como: treinamento de professores; incentivo ao estabelecimento de escolas; em diálogo com autoridades nacionais, investir na criação de perímetros de proteção de estruturas destinadas ao ensino; dialogar com as comunidades afetadas para esclarecer a importância de as crianças frequentarem as escolas - com um especial foco na inclusão de meninas, crianças deficientes e outros grupos tradicionalmente excluídos; ensinar aos pais métodos de manutenção da higiene pessoal das crianças e como lidar com emergências médicas; e orientar maneiras de melhor gerenciar bens hídricos e elétricos.

Assim, combate-se com essa abordagem uma visão dicotomizada da atuação perante emergências, a qual priorizaria, num primeiro momento, o puro auxílio à preservação de vidas e, após alcançada uma estabilização, se buscaria a consecução dos direitos humanos sociais, culturais e econômicos - ligados, em sua essência, ao desenvolvimento. Com efeito, quando a crise não consiste mais em situação transitória, as fronteiras entre essas necessidades tornamse opacas, de forma que uma não pode sobrepujar outra, mas que, sim, devem ser atendidas concomitantemente (DAVIS, 2015, p. 39).

A UNICEF é grande incentivadora dessa visão de atuação fundada em direitos humanos, vendo grandes vantagens nessa abordagem. Ela defende, inclusive, que ela serve para fortalecer a neutralidade da organização em situações de emergência complexas. Isso decorre do fato de que, ao pautar sua atuação em patamares internacionais estabelecidos nos instrumentos de direitos humanos regionais e internacionais, a organização consegue manter-se universal e coerente (ONU, 2000, p. 04).

Essa abordagem, com efeito, consiste na mais benéfica, pois, ao resguardar desde um primeiro momento a educação, estabelecendo-a como um direito humano, há a oportunidade de criar-se proveitosos dividendos sociais. Isso porque educação de qualidade contribui de maneira direta para o desenvolvimento sustentável e para a estabilidade social, econômica e política de uma sociedade. Ela ajuda a diminuir o risco de conflitos violentos, vez que favorece uma maior coesão social com a criação de oportunidades para aqueles que normalmente são excluídos, e ajuda a apoiar processos de construção da paz (ANDERSON et al., 2011, p. 88). 
Assim, podemos afirmar que mais importante do que o restabelecimento de um status quo prévio à emergência em si, a abordagem de direitos humanos que dá prioridade à educação desde o momento inicial das atuações humanitárias permite que esses contextos possam servir como oportunidade para que as autoridades nacionais transformem seus sistemas educacionais e criem as condições viabilizadoras de um desenvolvimento sustentável. Isso serviria para criar novas oportunidades para grupos que geralmente são excluídos, como meninas, adolescentes, crianças com deficiências, refugiados e deslocados internos. Assim, a crise serviria para a criação de dividendos sociais e para o desenvolvimento sustentável, resultando em melhoras no acesso e qualidade da educação que contribuirão, à longo e médio prazo, para a melhora da saúde local, diminuição da pobreza, melhor gestão hídrica e energética, entre outros indícios de desenvolvimento.

\section{CONCLUSÃO}

Conforme constatado pela análise acime exposta, o direito à educação recebeu constante e crescente destaque nos últimos anos no que tange seu papel no desenvolvimento sustentável das comunidades e dos países. Tal papel não é atenuado em momentos de crise: pelo contrário, as emergências criam novas situação de vulnerabilidade e exposição para os indivíduos mais vulneráveis das comunidades, fazendo ser ainda mais necessário que o direito à educação seja priorizado.

De fato, nesses contextos o emprego de medidas que assegurem a inclusão e ampliação de acesso à educação pode servir como armas potentes para a pacificação social, segurança e preservação da saúde dos indivíduos afetados. Os resultados imediatos serão facilmente percebidos, com, por exemplo, maior segurança para crianças que estejam em instalações dedicadas à escolas e menores chances de conscrição militar ou para milícias dos jovens regularmente partes de instituições de ensino.

Mais profundos, no entanto, são os efeitos que só podem ser sentidos à médio e longo prazo, como as maiores chances de pacificação dos conflitos e redução de índices de pobreza. 


\section{A IMPORTÂNCIA DO DIREITO À EDUCAÇÃO PARA A CONSECUÇÃO DO DESENVOLVIMENTO SUSTENTÁVEL EM CONTEXTOS DE EMERGÊNCIA}

Contudo, o primeiro passo deve ser dado no sentido da construção de uma sociedade que se desenvolve sustentavelmente, o qual consiste, independentemente da estabilidade da comunidade naquele momento, da priorização da educação. A ocorrência de crises ou emergências em nada muda esse quadro e apenas servem para tornar ainda mais premente que seja dado não mais um mero passo, mas, sim, um salto em direção desse futuro melhor.

\section{REFERÊNCIAS}

ANDERSON, Allison; HOFMANN, Jennifer; HYLL-LARSEN, Peter. The Right to Education for Children in Emergencies. International Humanitarian Legal Studies 2, pp. 84126, 2011

BRASIL. Decreto 99.710, de 21 de novembro de 1990. Promulga a Convenção sobre os Direitos da Criança. Diário Oficial da União, 22 nov. 1990

BRASIL. Decreto 591, de 06 de julho de 1992. Promulga o Pacto Internacional sobre os Direitos Econômicos, Sociais e Culturais. Diário Oficial da União, 07 jul. 1992

BRASIL. Decreto 849, de 25 de junho de 1993. Promulga os Protocolos I e II de 1977 adicionais às Convenções de Genebra de 1949, adotados em 10 de junho de 1977 pela Conferência Diplomática sobre a Reafirmação e o Desenvolvimento do Direito Internacional Humanitário aplicável aos Conflitos Armados. Diário Oficial da União, 28 jun. 1993

BRASIL. Decreto 4.388, de 25 de setembro de 2002. Promulga o Estatuto de Roma do Tribunal Penal Internacional. Diário Oficial da União, 25 set. 2002

COMISSÃO MUNDIAL SOBRE O MEIO AMBIENTE E DESENVOLVIMENTO. Relatório Nosso Futuro Comum. 20 mar. 1987. Disponível em: < http://www.undocuments.net/our-common-future.pdf>. Acesso em: 20 jul. 2017

CORTE INTERAMERICANA DE DIREITOS HUMANOS. Opinião Consultiva OC17/2002. 28 ago. 2002. Disponível em: <

http://www.corteidh.or.cr/docs/opiniones/seriea_17_ing.pdf>. Acesso em: 18 mar. 2018

DIDHAM, Robert J.; OFEI-MANU, Paul. "The Role of Education in the Sustainable Development Agenda: Empowering a Learning Society for Sustainability through Quality Education”. In: BENGTSSON, Magnus; OLSEN, Simon Hoiberg; ZUSMAN, Eric (Eds.). Achieving the Sustainable Development Goals: From Agenda to Action. Hayama: Institute for Global Environmental Strategies, 2015, pp. 95-134

DAVIS, Gabrielle Mary. Living with Landmines: Mine action, Development and Wellbeing in post-conflict societies - a case study in Cambodia. Bath: Universidade de Bath, 2015. Tese 
FOX, Fiona. New Humanitarianism: Does it Provide a Moral Banner for the 21 Century? Disasters, v. 25, n. 4, pp. 275-289, 2001

FREITAS, Juarez. Sustentabilidade: direito ao futuro. 3. ed. Belo Horizonte: Fórum, 2016 HAUSLER, Kristen; URBAN, Nicole; MCCORQUODALE. Protecting Education in Insecurity and Armed Conflict: An International Law Handbook. LONDON, British Institute of International and Comparative Law, 2012

MCKEOWN, Rosalyn. Education for Sustainable Development Toolkit. Jul. 2002. Disponível em: <http://www.esdtoolkit.org>. Acesso em: 27 mar. 2018

UNESCO. Sustainable Development Begins with Education. 2014. Disponível em: < http://unesdoc.unesco.org/images/0023/002305/230508e.pdf >. Acesso em: 18 mar. 2018 UNESCO. Education 2030 Incheon Declaration. 2015. Disponível em: <

http://unesdoc.unesco.org/images/0024/002456/245656E.pdf>. Acesso em: 27 mar. 2018 UNESCO. Education for Sustainable Development Goals Learning Objectives. 2017.

Disponível em: < http://unesdoc.unesco.org/images/0024/002474/247444e.pdf>. Acesso em: 27 mar. 2018

UNESCO. International Standard Classification of Education. Nov. 1997. Disponível em: < http://www.unesco.org/education/information/nfsunesco/doc/isced_1997.htm>. Acesso em: 01 jul. 2017

ORGANIZAÇÃO DAS NAÇÕES UNIDAS. Declaração Universal dos Direitos Humanos. 10 dez. 1948. Disponível em: <

http://www.ohchr.org/EN/UDHR/Documents/UDHR_Translations/por.pdf>. Acesso em: 01 jul. 2017

ORGANIZAÇÃO DAS NAÇÕES UNIDAS. Report of the Committee on the Rights of the Child on its General Discussion on the Right of the Child to Education in Emergencies

Situation. 19 de setembro de 2008. Disponível em: < http://www.right-toeducation.org/sites/right-to-education.org/files/resourceattachments/CRC_Report_Right_of_the_Child_to_Education_in_Emergencies_2008.pdf>. Acesso em: 01 jul. 2017

ORGANIZAÇÃO DAS NAÇÕES UNIDAS. UNICEF Core Corporate Commitements in Emergencies. UN DOC E/ICEF/2000/12. Maio de 2000. Disponível em: <

http://www.unicefinemergencies.com/downloads/eresource/docs/Human\%20Rights\%20Base d\%20Approach/Is\%20UNICEF\%20up\%20for\%20the\%20Challenge.pdf>. Acesso em: 05 jul. 2017

PISENTIN, Elena. The Right to Education in Emergency Situations: A Rights-Based Assessment on the Humanitarian Response after the Earthquake in Haiti. Pádova: Università Degli Studi di Padova, 2014. Dissertação

PROGRAMA DAS NAÇÕES UNIDAS PARA O DESENVOLVIMENTO. Mine Action for Sustainable Development. Nova York: UNDP, 2016 